\section{The meaning of being young with dementia and living at home}

\author{
Dag Rostad,' Ove Hellzen, 2,3 \\ Ingela Enmarker ${ }^{2,4}$
}

'Psychiatric service, Rennebu municipality

Rennebu, Norway; ${ }^{2}$ Center for Care

Research, Mid-Norway; ${ }^{3}$ Department

of Health Sciences, Mid Sweden

University, Sundsvall, Sweden; ${ }^{4}$ Faculty

of Health Sciences, Nord-Trondelag

University College, Namsos, Norway

\section{Abstract}

Studies that explore the subjective experiences of younger people with dementia living at home are rare. Therefore, the aim of this study was to gain an understanding of the lived experience of younger persons ( $<65$ years) who lived at home and suffered from earlyonset dementia, and the meanings that might be found in those experiences. The researchers conducted a qualitative study using a phenomenological hermeneutic approach. Data were collected through narrative interviews with four informants. Two men and two women ages 55 to 62 participated. Three of the informants lived with their spouses, and one lived alone, close to his children. The informants' subjective experiences revealed the following four key themes: entrapment by circumstances, loss of humanity, the preservation of hope and willpower, and the desire to ensure one's quality of life. These themes provide a deeper understanding of the experiences of younger people with dementia who live at home. The theme of preserving hope and willpower rebuts prejudicial contentions that life with Alzheimer's syndrome does not have anything more to offer and may be seen as diminishing a patient's humanity. Patients' autonomy and self-determination should not be ignored. In all phases of the progression of dementia, the person in charge of giving care to the relative with dementia should be ethically aware of and reflective to the progress of his/her illness.

\section{Introduction}

In Scandinavia, approximately 350,000 people suffer from dementia. About 3 percent of these people are less than 65 years old and have been diagnosed with early-onset dementia. In Norway, it is estimated that 1400 citizens suffer from early-onset dementia, but no prevalence studies have been carried out, and the number of unreported cases is unknown. ${ }^{1}$ When studying the experiences of people with early-onset dementia, a number of social challenges should be taken into consideration, such as the changes in relationships between dementia clients and their immediate families, ${ }^{2,3}$ awareness of life changes, ${ }^{4}$ feelings of being socially isolated and useless, ${ }^{5}$ emotional and mental affliction in the form of depression, ${ }^{6,7}$ and inactivity and lack of meaningful tasks in the absence of an active working life. ${ }^{8}$ However, Beattie et al..$^{9}$ pointed out that most of the conclusions of research on younger people with dementia were based on the perspectives of health professionals and their relatives, and that little attention has been given to the experiences of the affected people themselves. A few recent studies use affected persons' own experiences to provide insight into how younger people with dementia experience living with this disease, but more are needed. In Johannessen and Möller's ${ }^{1}$ study, the informants described their progress towards a medical diagnosis of dementia, detailing memory losses, failures to cope with the tasks of daily living, and struggles upon receiving the diagnosis. They also described the difficulties of developing dementia at a relatively young age, relating how this affected their self-image as well as their social interactions with others. In another recent study, ${ }^{10}$ similar results indicated that the diagnosis of dementia was a particular area of concern, as well as coping with others' reactions when receiving the diagnosis.

Following the Norwegian government's national plan for dementia, ${ }^{11}$ most people who suffer from early-onset dementia live at home. Living at home can offer the security of familiar rooms and items, ${ }^{12}$ it may increase opportunities to engage in a familiar community and meaningful relationships, ${ }^{13}$ but it may also lead to boredom and inactivity. ${ }^{8}$ Therefore, the aim of this study was to gain an understanding of the lived experiences of younger persons ( $<65$ years) who lived at home and suffered from early-onset dementia, and the meanings that could be found in their experiences.

\section{Materials and Methods}

In order to understand the lived experiences of people with early-onset dementia, the study employed an inductive qualitative approach. ${ }^{14}$ This method focuses on individual meaning and the importance of understanding the complexity of the situation at hands. ${ }^{15}$ The present study used a method of phenomenological hermeneutic analysis inspired by Lindseth and Norberg. ${ }^{16}$ The interpreted data represented personal stories about each informant's experiences; that is, these experiences are unique and not to be generalized.
Correspondence: Ingela Enmarker, Faculty of Health Sciences, Nord-Trøndelag University College, Namsos, Norway, Box 2501 N0-7729 Steinkjer, Norway.

Tel. +47.74212349 - Fax: +47.74212301

E-mail: ingela.enmarker@hint.no

Key words: dementia, living at home, early-onset dementia, interview, phenomenological hermeneutic analysis.

Acknowledgments: we extend our thanks to the informants who shared their thoughts and reflections with us.

Contributions: the first author conducted the narrative interviews. All three authors took part in the analysis and interpretation of data as well in writing the manuscript.

Conflict of interests: the authors declare no potential conflict of interests.

Received for publication: 2 April 2013.

Revision received: 13 June 2013.

Accepted for publication: 14 June 2013.

This work is licensed under a Creative Commons Attribution NonCommercial 3.0 License (CC BYNC 3.0).

CC Copyright D. Rostad et al., 2013

Licensee PAGEPress, Italy

Nursing Reports 2013; 3:e3

doi:10.4081/nursrep.2013.e3

\section{Research context and participants}

The inclusion criteria for the informants were: aged below 65 years and diagnosed with dementia, living in his or her own home, able to understand the study and answer questions for the interview, and able to give informed consent. Four people, two women and two men aged 55 to 62 years and living in rural Norway, agreed to participate; written consent was obtained. Three of the informants lived with their spouses, and one lived alone. One of the informants had received the diagnosis recently, while the others had been diagnosed two to four years earlier. They were classified by medical staff in the healthcare centers as having mild to moderate dementia. The main characteristics of the participants are summarized in Table 1.

Recruitment was performed by a health coordinator who had prior contacts with dementia groups. This was done to ensure the informants' integrity and to prevent unnecessary contact. The health coordinator contacted people who met the inclusion criteria with a request for participation and gave them both written and oral information about the study. The researcher who had experience working with dementia patients contacted the potential participants to discuss the study further only when interest, opportunity, and access were 
granted. Once these criteria were met, new requests for participation were offered; and consent forms were signed. Interviews were performed only when consent from the participants had been obtained.

\section{Data collection}

Data were collected through narrative interviews with broad open-ended questions. ${ }^{17}$ Narrative interviews are especially suited to research studies investigating the importance of identity, lifestyle, culture, and life history, and also more specifically when dealing with people's lived experiences and attempting to understand their health conditions. ${ }^{18}$ The informants were encouraged to speak freely and in as much detail as possible about their subjective experiences in their everyday lives. The intention was to create a normal, everyday conversation; the opening question was Can you tell me about an ordinary day in your life? Each informant was interviewed once. Two informants were interviewed at their own homes; one informant was interviewed at a welfare center; and one informant at a daycare center. All interviews, except one, were recorded and transcribed verbatim. The interviews were performed in 2010 , lasting about 40 to 60 min, and were conducted in the Norwegian language.

\section{Data analysis}

The narrative interviews were analyzed using a phenomenological hermeneutic approach inspired by the philosopher Paul Ricouer. ${ }^{16}$ This approach engaged the phenomenological philosophy of hermeneutic interpretation in a dialectical process. This meant that the interpretation of the text consisted of a dialogue of questions and answers, arguments, and counter-arguments, with the purpose of finding the content of each term. Interpretation moved back and forth between understanding and explanation, allowing a more comprehensive understanding to be achieved. ${ }^{17}$ The goal was to interpret, explain, and understand the importance of phenomena. ${ }^{16,19}$ According to Lindseth and Norberg, ${ }^{16}$ the analysis process included three phases. The first step involved a naïve (passive) reading of the text. In this study, the texts from which the initial understanding was derived were read several times. This created a preliminary interpretation of the experiences of younger people with dementia who lived at home.

The next phase, structural analysis, consisted of a thematic analysis of text. This step is regarded as the methodological part of the interpretation, offering an opportunity to confirm or reject the naive understanding. The texts were read several times and then categorized into meaning units based on different stories. The goal was to find topics that might be understood to convey essential meanings about the informants' worlds. The structural analysis phase was necessary to move from the naive understanding to a critical interpretation, progressing from a superficial to a deeper form of interpretation. ${ }^{20}$

In the final step, the texts were interpreted as a whole in light of the understanding obtained from the naive reading, structural analysis, and the researcher's prior understanding. ${ }^{21}$

\section{Methodological considerations}

The first author (DR) carried out the interviews. To ensure the trustworthiness of the findings, all three authors read the interview transcripts individually, followed the path of analysis from naïve reading to structural analysis, and then interpreted the whole. Finally, the authors discussed the analysis together until consensus was established.

\section{Ethical considerations}

The study was approved according to the Health Research Act $\S 10$ by the Regional Ethics Committee for Medical and Health Research South East D (2010/1114 - 1 Living at home). Participants were informed ahead of time, both orally and in writing, of the purpose and procedure of the study. The participants were granted confidentiality, and written consent was established. If they wished, the informants had the opportunity to consult trained personnel when their story-telling created a considerable level of distress.

\section{Results}

\section{Naïve reading}

The informants described their existence as chaotic. They found themselves in a contradictory state in which they were losing contact with some aspects of the human condition, while still struggling to be human. The disease's progression passed unnoticed over time. Getting the diagnosis felt wrong, and they felt lonely and powerless. This situation reflected the feeling of being trapped by cir-

Table 1. Major characteristics of participants.

\begin{tabular}{|c|c|c|c|c|c|c|}
\hline $\begin{array}{l}\text { Case no. and } \\
\text { gender }\end{array}$ & $\begin{array}{l}\text { Age } \\
\text { (years) }\end{array}$ & Diagnosis & Profession & Family status & Housing & Function/home care \\
\hline (1) Female & 55 & $\begin{array}{l}\text { Vascular } \\
\text { dementia }\end{array}$ & Self-employed & $\begin{array}{l}\text { Married; husband is } \\
\text { senior citizen; } \\
\text { adult daughter nearby }\end{array}$ & Farmhouse & $\begin{array}{l}\text { Physically active; needs some } \\
\text { help from husband; mentally active; } \\
\text { narrates freely and clearly about her } \\
\text { situation; does not want home care } \\
\text { nursing; day care in home once a week }\end{array}$ \\
\hline (2) Female & 58 & $\begin{array}{l}\text { Alzheimer's } \\
\text { disease }\end{array}$ & $\begin{array}{l}\text { Health care } \\
\text { worker }\end{array}$ & $\begin{array}{l}\text { Married; working husband; } \\
\text { adult son lives far away }\end{array}$ & Private flat & $\begin{array}{l}\text { Physically active; restless and } \\
\text { wandering; mentally active; starting to } \\
\text { have some difficulty finding words; } \\
\text { home care nursing; day care in home } \\
\text { once a week }\end{array}$ \\
\hline (3) Male & 62 & $\begin{array}{l}\text { Alzheimer's } \\
\text { disease }\end{array}$ & $\begin{array}{l}\text { Restaurant } \\
\text { worker }\end{array}$ & $\begin{array}{l}\text { Widower; two adult } \\
\text { daughters nearby }\end{array}$ & Private flat & $\begin{array}{l}\text { Physically active; mentally active; } \\
\text { narrates freely and clearly about his } \\
\text { situation; home care nursing and } \\
\text { domestic help; day care in home once a } \\
\text { week }\end{array}$ \\
\hline (4) Male & 60 & \multicolumn{2}{|c|}{ Alzheimer's diseaseIndustrial worker } & Married; working wife & New private flat & $\begin{array}{l}\text { Physically inactive; mentally passive, but } \\
\text { narrates freely and clearly about his } \\
\text { situation; day care in home once a week }\end{array}$ \\
\hline
\end{tabular}


cumstances. The informants spent a lot of energy maintaining a normal situation in daily life and preserving their hope and willpower. Their statements also revealed their feelings about their dependence on professional assistance. Being able to stay at home was essential in order to continue experiencing a good life, particularly security and a sense of well-being. At the same time, they said that staying at home gave them not only a sense of meaning but also frustration and anger at the experience of being idled. They often found themselves in a situation where they sat and waited for something, but they did not know what they were waiting for.

\section{Structure analysis}

The following four themes are presented in the analysis: i) entrapment by circumstances; ii) loss of humanity; iii) the preservation of hope and willpower; iv) the desire to ensure one's quality of life.

\section{Entrapment by circumstances}

All the informants expressed the feeling that they had been placed into a situation that they were unable to change. They did not notice the progress of their disease cognitively, but they experienced multiple negative emotional reactions before and after getting the diagnosis. Although the informants experienced great trials as a result of this serious illness, they tried to adjust and accept their situations.

Sub-theme: lack of cognitive consciousness of the disease's progress

None of the informants noticed the progress of their disease. The paths to their current situations faded, as the disease's process was gradual and they were not able to trace its contours.

It happened over time, so that I didn't notice (case 2).

\section{Sub-theme: experiencing emotional stress}

However, the participants described a number of reactions upon their discovery that they suffered from a serious and progressive disease. A certain doubt was expressed when they described their experiences:

... this is unreal because I'm not so old (case

1)... it was almost horrible (case 2).

... damn, now it's done (case 4).

Now the world has come apart, and I was shocked when it happened (case 3).

Sub-theme: being able to live with the diagnosis

Participants indicated that they had reached an understanding, attempted to control the situation, and tried not to focus on the negative emotional reactions, instead focusing on a sense of acceptance. They tried to adjust to their own situations. There was no way to overcome the disease; they should carry on, bear the situation and take each day as it comes.

But that is how life is, and one just has to live this way (case 3).

\section{Loss of humanity}

Informants experienced life as a state of chaos, and their explanations highlighted the complex range of losses that they experienced, including loss of self-identity, self-esteem and self-respect, and self-determination, as well as the loss of social relationships. Controlling and coming to terms with these losses took a lot of energy and were accompanied by a series of emotional outcomes. The informants' experiences of being human were affected. A lack of knowledge about the symptoms and progression of the disease was also a common experience.

\section{Sub-theme: losing self-determination and becoming dependent}

Informants' stories revealed a reduced existence and a minimized world - coping with their situations takes a lot of energy. The informants described the entrance into a phase of life where others took control of their health and treatment as a major assault against their ability to participate in society and made their own decisions. At the same time, they knew and/or remembered little about their situations. They also remembered little about the information they had been given and how to handle it. The decline was visible and it affected their self-determination and independence.

It is my wife who forced the diagnosis upon me; it was only my wife the doctor listened to (case 4).

Another man describes his changed situation: It is wrong; I am the same as before (case 3 ). Several of the informants described the loss of their driver's license, expressing sadness at their increased dependency. One of the women claimed:

The fact that they took my driver's license is the biggest change. To lose the license makes me dependent on others and the loss of my license worsens the situation (case 1).

\section{Sub-theme: reduced activities and social interactions}

Several informants wished to have a good life and they expressed this desire clearly. However, the loss of their social networks made this a challenge. Difficulty in establishing and sustaining social interactions contributed to their experiences of no longer being part of society. Progressive reduction of functioning as the disease took its toll highlighted those declines even further. Several informants emphasized the importance of having something to do and expressed their feel- ings of passivity and ineffectiveness.

I feel a lot of meaninglessness, depression, and anger. I sit a lot and wait, but I do not know what I'm waiting for. I would like to have something to do (case 4).

I have difficulty with social contact, problems communicating and [having] a good time, but [I] would like to have someone to talk to (case 2).

... losing work led to losing my friends (case 3 ).

Sub-theme: declining to develop affective feelings

Informants experienced losses that reduced the value they placed on living. Their stories showed that many of them felt sorrow about this state of loss.

Not being able to do things [I] could do before makes me irritated. All the losses feel suffocating (case 4).

Not being able to succeed in doing things I prefer to do makes me upset (case 1).

\section{The preservation of hope and willpower}

Almost every informant exhibited a strong feeling of determination and hope for survival. None of them had given up; in struggling day after day, they demonstrated impressive strength. Having dreams and interests appeared to play a significant role in keeping their spirits alive. Although they seemed to be aware of the fact that their disease could not be cured, their dreams and interests were perceived to offer an opportunity to have a good life.

\section{Sub-theme: maintaining an identity and self-reliance}

The informants' descriptions revealed a strong desire to prove that they could cope with normal life. Although they were aware of the changes in their life situation and the fact that their independence was endangered by the disease, they related stories of taking initiative to preserve their faith and control their lives. These actions had already given them a certain sense that they could preserve their self-identities and maintain some forms of selfreliance.

But I'll still be energetic and not give up... I am not going to just sit down (case 3 ).

I have decided; I have made [up] my mind, I will go as far as I will myself to (case 2).

Receiving help from others made them feel a strong desire to remain self-reliant and independent. A woman said about her meeting with home care personnel:

I had a home care service before, but it was just chaos. The personnel came and she/he ordered me to go to the bathroom, an experience I found quite uncomfortable and anxietyinducing. I found out that I could manage better by myself without this service (case 1). 


\section{The desire to ensure one's quality of life}

Being able to live at home was considered necessary for a good life. Not being able to live at home threatened the informants' independence. Living at home gave them a good quality of life because they lived in known and safe surroundings.

I manage well at home, with some help (case 1).

I will be fine as long as I can live at home (case 3).

I can manage going to the store myself. I've managed well the whole time, at least at home, where I feel secure and things are familiar (case 2).

However, because of the disease, one of the informants had to move to a new place to live, and he did not view the new home as being as safe as his previous home was.

I don't like and do not enjoy the new apartment. I have a feeling that the neighbors are watching my activities. I miss the place I lived before, where I could sit down in peace and drink my coffee on the balcony. There was more space as well, and I had something to do there (case 4).

\section{Comprehensive understanding}

The informants' stories revealed a number of complex experiences relating to the changes in their life situations and experiences of being human. Our interpretation suggested that younger people with dementia who lived at home felt like they were in a situation characterized by frustrations, despairs, and meaninglessness as a result of the loss of their humanity. However, they still showed courage and struggled to maintain their humanity and self-value.

\section{Discussion}

The meaning of the informants' subjective experiences revealed the following four key themes: entrapment by circumstances, loss of humanity, the preservation of hope and willpower, and the desire to ensure their quality of life. The theme of entrapment by circumstances is strongly linked to the experience of being bound by an incurable and serious progressive disease. Dementia and other diseases related to cognition involve a series of complex changes in a person's ability to live her/his daily life. The informants' stories verify a wide series of reactions and actions due to these circumstances, both before and after the diagnosis. Researchers have suggested that younger people with dementia are more aware of the fact that something is wrong than older people with the disease. ${ }^{22}$ However, none of the informants in this study were able to give an explicit description of the progress of their own dementia. Instead, they described a range of emotional reactions to the knowledge of their diagnosis. Questions about what a person with dementia wants to be told remain largely unanswered. ${ }^{23}$ Undergoing an extensive medical examination and receiving a correct diagnosis are the keys to understanding one's diagnosis in the early stages. This will activate further choices in terms of independence, planning, and adequate follow-up. ${ }^{23}$

The meaning of the informants' narratives also demonstrates that people suffering from sudden and/or incomprehensible events try to regain some balance through their actions. Antonovsky ${ }^{24}$ and Lazarus ${ }^{25}$ relate the experience of stressful situations to individuals' previous experiences. Depending how a person understands what has happened, the coping process might entail reconstructing meaning in life, trying to regain social roles and functions, or trying to manage one's life despite the illness. Even with a serious illness, people can transform the experience of chaos into something organized to help them to deal with their situations. ${ }^{26-28}$ Corbin and Strauss ${ }^{29}$ described how experiences and assigned meanings affect social relationships and practical matters, which are both separate from the disease and, at the same time, part of it. Several studies describe coping strategies in people with dementia. ${ }^{30,31}$ However, in this study, informants' narratives reflect conflicting meanings, from entering a recovery phase after learning of the diagnosis to being irritated at the experience of personal loss. In order to survive this emotional conflict, individuals transform reality. ${ }^{32}$

The theme of the loss of humanity was derived from the informants' descriptions of a series of incidents that weakened their experiences of being human. As in studies by Macquarrie $^{33}$ and Steeman et al., ${ }^{31}$ the results show that younger people with dementia experience losses in mastery of functions and abilities. Those experiences affect the informant's self-determination and independence. Several of the informants described the loss of their driver's license with great sadness. This increased their dependence and the feeling that they were trapped in their homes and limited their self-determination. The informants' descriptions also highlight the experience of lacking meaningful activity. This experience is described as frustrating and meaningless and seen to cause social isolation and loneliness. Inability to work any longer reduces social interaction, alienates one from the community, and produces a sense of worthlessness. Clare $^{34}$ and Menne et $a l^{35}$ describe similar findings. Steeman et al. $^{31}$ found that social interactions and sense of being a part of a community are of great importance in determining one's understanding of oneself as a valuable human.

Having a disease related to dementia does not prevent one from being hurt and feeling annoyed at one's inability to function as before. As in Phinney's ${ }^{36}$ study, the informants in this study experienced feelings of anger and frustration at this lack. Eriksson ${ }^{37}$ interpreted and discussed the losses caused by dementia diseases, concluding that the problems that follow in the wake of such declines and suffering are those most central to the human experience. People affected by chronic diseases find that certain life histories are interrupted, their sense of coherence is undermined, and the future becomes uncertain and unpredictable. ${ }^{38}$

The theme of the preservation of hope and willpower is expressed in the informants' stories that discuss their desire to be acknowledged and valued as humans. The theme defies all preconceptions that life with dementia offers no rewards and runs counter to human dignity.

As younger people affected by dementia will lose most of their characteristic life roles, ${ }^{39}$ the opportunity to fulfill their interests and hobbies can offer a means of preserving their senses of self and creating new roles. Kielhofner ${ }^{40}$ noted that when young people with dementia are devoted to activities that are personally useful, these activities provide a positive effect in the form of independence and preserve individuals' personalities.

Conversely, hope and willpower are considered to be forces that help cope with the situation and the experience of conflicting emotions through the cultivation of sacred moments and plans. The informants' stories are similar to findings in other studies in which hope is defined as an inner resource and mechanism for coping. ${ }^{41,12}$ According to Frankl, ${ }^{43}$ humans' search for meaning in life can help them to cope with loss. Erikson ${ }^{44}$ found that hope is essential for human life and ego maintenance. When one is affected by dementia, good moments can create nice days. By possessing hope and willpower, one may comprehend one's situation and experience as gaining something, have great fun, and in many ways enjoy a good quality of life.

Negative experiences with professional assistance increase the desire to be independent and self-reliant. Other studies describe a similar negative experiences and judgments due to the influx of many aides; ${ }^{45}$ criticisms related to a lack of time, a lack of continuity, and a lack of available services; ${ }^{46}$ and feelings of worthlessness. ${ }^{45}$ In addition to the difficulties they experienced as a result of practical functional impairment, informants' difficulties reflect their need to preserve their identities and participate in society. Such assistance is 
available through state auxiliary home services, a term that covers several services, offering either an auxiliary at one's own home, or at day care centers or institutions. ${ }^{47}$ Auxiliary services have been promoted around the world for more than 20 years; they have offered positive experiences to many and provide a rational basis for maintaining quality of life, identity, socialization, security, and activity levels. ${ }^{47}$

However, Chaston ${ }^{48}$ found that younger people with dementia are more physically active and have different needs and interests than older people. In general, judging from their stories, the informants have different individual needs and functional levels; professional help is experienced very differently from one person to another. To a very large extent, they depend on their caregivers and their caregivers' ability to be present to meet and fulfill their needs.$^{49}$ Care and support must be given in a way that complies with the wishes and needs of each individual. This means that health professionals have to listen to people with dementia and learn from them in order to understand how they perceive their situation and what kind of support they need. ${ }^{49}$

The desire to ensure one's quality of life refers to the informants' subjective experiences of confidence as well as the permanent and secure perspective gained through comfort with one's home surroundings. Therefore, the phrase being at home refers to more than the physical properties involved.

On one hand, the informants describe the experience of being able to live in their own accommodations as a positive one. Living at own home offers informants feelings of positivity, happiness, and security. The home can create a feeling of security and act as a place where a person experiences recognition. ${ }^{12}$ The importance of feeling at home may also help people experience peace of mind and the sense of being at ease with themselves. People can experience contact with a familiar community as a meaningful relationship. ${ }^{13}$ If a younger person with dementia is recognized as an important person, this could make that person feel like a part of the community and offer meaning to that person's life, in spite of the disease. When attachment to a place such as a home or a room becomes stronger, humans begin to identify themselves with that place. ${ }^{50}$

On the other hand, changes in environment create negative experiences of the disease. The sense of missing familiar and known surroundings, as well as dissatisfaction with new surroundings, was palpable. Dementia also affects people's perception of their environment. Particularly for younger people with dementia, their surroundings should be familiar and represent something known, understandable, and manageable. As a result of increasing cognitive disability, a person's perception and assessment of the environment changes during the course of the disease. ${ }^{51,52}$

If it is not possible to adjust their accommodations, younger people with dementia will experience isolation at home; as a result of the disease's progression, a move to an institution might be necessary. ${ }^{47}$ However, it is generally preferable for people to remain in contact with the community, and when this is not too challenging, emotional rewards will accrue not only for younger people with dementia but also for many other people. ${ }^{47}$

\section{Methodological considerations}

The results of this research study must be seen as a unique product of the personal narratives used as texts and the theoretical apparatus employed; they also reflect our own personal experiences to some degree. Each of the informants' unique and personal lived experiences contributed to the process of interpreting the results. The main restriction affecting the study is the small number of informants. It was difficult to recruit informants, since only a few registered cases of dementia in younger people are diagnosed and known of by health care centers in this rural area. In addition, the ethical obligation to be cautious about causing patient distress may have reduced the persistence of recruitment efforts.

Moreover, since persons with early-onset dementia are usually diagnosed in the later stages of the disease, ${ }^{1}$ we can assume that there are a number of unknown cases. Nevertheless, the participants' characteristics vary, as reflected in their information-rich narratives. The purpose was not to generalize, but to contribute to a process of generating meanings and teasing out nuances that can amplify the quality of informants' lived experiences and enrich our knowledge about those experiences, which is currently scarce. The knowledge that emerges will be as important and meaningful as any other knowledge..$^{53}$

\section{Conclusions}

When a person is suffering from dementia, it is assumed that the person lacks an awareness of his or her situation. This can mean that person's autonomy and self-determination are ignored or not considered, and that they experience a lack of respect. Our interpretations of the informants' experiences, however, show that despite experiencing complex problems in their daily lives with remembering and maintaining their own needs, they desire to be independent and have self-determination. Therefore, in all phases of progression of dementia, the person in charge of caring for the person with dementia should reflect on and maintain ethical awareness about the care recipient's expectations and needs. The fact that people with dementia who live at home may not want to receive help also creates a complex ethical dilemma for further investigation and discussion.

\section{References}

1. Johannessen A, Möller A. Experiences of persons with early-onset dementia in everyday life: a qualitative study. Dementia 2011. [Epub ahead of print].

2. Cox S, Keady J. Younger people with dementia: Planning, practice and development. London and Philadelphia: Jessica Kingsley Publishers; 1999.

3. Brod M, Stewart AL, Sands L, Walton P. Conceptualization and measurement of quality of life in dementia: the dementia quality of life instrument (DQoL). Gerontologist 1999;1:25-9.

4. Tindall L, Manthrope J. Early onset dementia: A case of ill timing? J Ment Health 1997;6:237-9.

5. Williams 0, Keady J, Nolan M. Youngeronset Alzheimers's disease; learning from the experience of one spouse carer. J Clin Nurs 1995;4:31-6.

6. Lyketsos CG, Lopez 0, Jones B, et al. Prevalence of neuropsychiatric symptoms in dementia and mild cognitive impairment: results from the cardiovascular health. JAMA 2002;288:1475-83.

7. Rosness TA, Barca ML, Engedal K. Occurrence of depression and its correlates in early onset dementia patients. Int J Geriatr Psych 2010;25:704-11.

8. Reed J, Cantley C, Clarke C, Stanley D. Services for younger people with dementia. Dementia 2002;1:95-12.

9. Beattie AM, Darker-White G, Gilliard J, Means R. Younger people with dementia care: a review of service needs, service provision and models of good practice. Aging Ment Health 2002;6:2005-12.

10. Pipon-Young FE, Lee Km, Jones F, Guss R. I'm not all gone, I can still speak: The experiences of younger people with dementia. An action research study. Dementia 2012;11:597-16.

11. Helse- og omsorgsdepartementet. Demensplanen 2015 [Norwegian Government Plan of Dementia 2015]. Oslo; 2007.

12. Svanström R. När livsvärldens mönster brister - erfarenheter av att leva med demenssjukdom. [When life texture ruptures - Experience of living with Dementia]. Växjö University Doctorial Dissertation (Dept. Nursing and social science). No 178; Acta Wexionensia 2009.

13. Zingmark K, Nordberg A, Sandmann PO. Experience of at-hominess and homesickness in patient with Alzheimer's disease. 
Am J Alzheimer Care Relat Disord Res 1993;8:10-6.

14. Patton MQ. Qualitative research and evaluation methods. 3th ed. London: Sage Publications; 2002.

15. Creswell JW. Research design. Los Angeles: Sage Publications; 2009.

16. Lindseth A, Nordberg A. A phenomenological hermeneutical method of researching lived experience. Scand J Caring Sci 2004; 18:145-53.

17. Enarsson P, Sandman PO, Hellzen 0. They can do whatever they want: meanings of receiving psychiatric care based on a common staff approach. Int J Qual Stud Health Well-being 2010;6:5296.

18. Claeson L. Tid for existentiellt meningsskapande: Kvinnors berättelser om sitt liv med allvarlig sjukdom. [Time and existential meaning-making: Women's narratives about living with serious illness] Doctoral dissertation. Department of Education, Stockholm University, S-10691 Stockholm: 2010.

19. Gustafson G, Nordberg A, Strandberg G. Meanings of becoming and being burnout - phenomenological hermeneutics interpretation of female healthcare personnel's narratives. Scand J Caring Sci 2008;22: 520-8.

20. Thompson JB, Ricouer P. Hermeneutics and the human science. Essays on language, action and interpretation Cambridge: University Press; 1994.

21. Ricouer P. From text to action. Essays in hermeneutics. Evanston: Northwestern University Press; 1991.

22. Woods B. Younger people with dementia: psychosocial interventions. In: Cox S, Keady J, eds. Younger people with dementia. Planning, practice and development. London and Philadelphia: Jessica Kingsley; 1999. pp 261-82.

23. Pinner G. Truth-telling and the diagnosis of dementia. Brit J Psychiatry 2000;174:14-5.

24. Antonovsky A. Unraveling the mystery of health: How people manage stress and stay well. San Francisco, CA: Jossey-Bass Publishers; 1987.

25. Lazarus R. Stress and emotion - a new synthesis. New York: Springer; 1999.

26. Clare L. We'll fight it as long as we can: coping with the onset of Alzheimer s disease. Soc Sci Med 2002;57:1017-29.

27. Harmann G, Clare L. Illness representations and lived experience in early-stage dementia. Qual Health Res 2006;16:484-02.

28. Mok E, Lai CKY, Wong FLF, Wan P. Living with early-stage dementia - the perspective of older Chinese people. J Adv Nurs 2007;59:591-600.

29. Corbin J, Strauss A. Unending work and care - managing chronic illness at home. San Francisco, CA: Josey-Bass Publishers; 1988.

30. Snyder L. Satisfactions and challenges in spiritual faith and practice for persons with dementia. Dementia 2003;3:299-13.

31. Steeman E, de Casterle BD, Godderis M. Living with early-stage dementia: a review of qualitative studies. J Adv Nurs 2006;6: 722-38.

32. Baltes P, Smith J. New frontiers in the future of aging: from successful aging of the young old to the dilemmas of fourth age. Gerontology 2003;49:123-35.

33. Macquarrie CR. Experience in early stage Alzheimer's disease: Understanding the paradox of acceptance and denial. Aging Ment Health 2005;5:430-41.

34. Clare L. Managing threats to self: awareness in early stage Alzheimer`s disease. Soc Sci Med 2003;57:1017-29.

35. Menne HL, Kinney JM, Morhardt DJ. Trying to continue to do as much as they can do. Dementia 2002;1:367-82.

36. Phinney A. Living with symptoms of Alzheimer's disease. In: Harris PB, ed. The person with Alzheimer's disease. Pathways to understanding the experience. Baltimore and London: The Johns Hopkins University Press; 2002. pp 49-74.

37. Eriksson K. Understanding the world of the patient, the suffering human being: the new clinical paradigm from nursing to caring. Adv Pract Nurs Q 1997;381:8-13.

38. Corbin J, Strauss AL. Accompaniments of chronic illness: changes in body, self and biological time. Res Sociol Health Care 1987;6:249-81.

39. Harris BP, Keady J. Selfhood in younger onset dementia: transitions and testimonies. Aging Mental Health 2009;13:43744.
40. Kielhofner G. Model of human occupation: theory and application, 4th Ed. Philadelphia, PA: Lippincott Williams and Wilkins; 2008.

41. Duggleby W, Wright K. Transforming hope: how elderly palliative patients live with hope. Can J Nurs Res 2005;37:70-84.

42. Elliott JA, Oliver IN. Hope, life and death: a qualitative analysis of dying cancer patients talk about hope. Death Stud 2009;33:609-38.

43. Frankl V. Man's search for meaning. London: Rider; 2004.

44. Erikson EH. Childhood and society, 2nd Ed. New York, NY: Norton; 1963.

45. Lystrup LS, Lillesveen B, Nygård A, Engedal K. Omsorgstilbud til hjemmeboende personer med demens. [Public social health services to persons with dementia living at home in Norway]. Tidsskrift for den Nor Lægeforening 2006;15:1917-20.

46. van Servellen G, Fongwa M, Mockus D'Errico E. Continuity of care and quality care outcomes for people experiencing chronic conditions: a literature review. Nurs Health Sci 2006;8:185-95.

47. Lee H, Cameron M. Respite care for people with dementia and their carers. Cochrane Database Syst Rev 2004;(2):CD004396.

48. Chaston E. Younger adults with dementia: A strategy to promote awareness and transform perceptions. Contemp Nurse 2010;34:221-9.

49. Kitwood T. Dementia reconsidered: the person comes first. Buckingham: Open University Press; 1997.

50. Gifford R. Environmental psychology: principles and practice. Canada: Optimal books; 2002.

51. Kellaher L. Shaping everyday life beyond design. In: Peace SM, Holland C, eds. Inclusive housing in aging and society innovative approaches. Bristol: The Policy Press; 2001. pp 215-34.

52. Perrin T. Occupational need in severe dementia: a descriptive study. J Adv Nurs 1997;25:934-41.

53. Malterud K. Kvalitative metoder i medisinsk forskning, en innføring [Qualitative Methods in Medical Research - An Introduction]. 4th ed. Oslo: Universitetsforlaget; 2008. 